\title{
PAPERS
}

\section{Patterns of gastritis in patients with gastro-oesophageal reflux disease}

\author{
D J Bowrey, G W B Clark, G T Williams
}

\begin{abstract}
Background-The cause of inflammation in cardiac mucosa at the gastrooesophageal junction (GOJ) is unclear, both gastro-oesophageal reflux disease (GORD) and Helicobacter pylori having been implicated.

Aims-To describe patterns of gastritis in patients with symptomatic GORD.

Methods-In 150 patients (126 normally located Z-line, 24 Barrett's oesophagus) with symptoms of GORD, biopsies were taken of the GOJ, corpus, and antrum. Inflammation was assessed using the updated Sydney System.
\end{abstract}

Results-For the 126 patients with a normally located Z-line, biopsies of the GOJ revealed cardiac mucosa in 96 , fundic mucosa in 29, and squamous mucosa in one. Inflammation in glandular mucosa at the GOJ was present in $99 / 125$ specimens (79\%), including $87 / 96$ (91\%) with cardiac mucosa and $12 / 29(41 \%)$ with fundic mucosa. Inflammation in fundic mucosa was closely related to $H$ pylori and active inflammation was only seen in its presence. Inflammation in cardiac mucosa was less closely linked to $\boldsymbol{H}$ pylori. When $\boldsymbol{H}$ pylori was present in cardiac mucosa (28/96, 29\%) active inflammation was usually present $(25 / 28,89 \%)$. However, active inflammation was also found in $34 / 68$ $(50 \%)$ cardiac mucosa specimens without H pylori. Overall, 28/87 (32\%) biopsies with carditis were colonised with $H$ pylori and 59/87 (68\%) were not. In H pylori colonised patients, inflammation was seen throughout the stomach, while in noncolonised patients, it was confined to cardiac mucosa.

Conclusions-Patients with symptomatic GORD had a high prevalence of carditis. This was of two types, $\mathrm{H}$ pylori associated and unassociated. Except on Giemsa staining, the two were morphologically identical, suggesting mediation by a similar immunological mechanism.

(Gut 1999;45:798-803)

Keywords: cardiac mucosa; carditis; gastrooesophageal junction; gastro-oesophageal reflux; Helicobacter pylori; inflammation
The reasons for the increasing incidence of adenocarcinoma of the lower oesophagus and gastro-oesophageal junction (GOJ) are unclear. ${ }^{12}$ Specialised intestinal metaplasia is accepted to have a premalignant potential when it is associated with a columnarised oesophagus measuring $3 \mathrm{~cm}$ or more in length..$^{3-10}$ The hypothesis that shorter lengths of specialised intestinal metaplasia underlie the genesis of adenocarcinoma at the GOJ has prompted clinicians to biopsy the "no go area" of the GOJ zone. With this approach, specialised intestinal metaplasia has been identified at this site in up to $25 \%$ of unselected patients undergoing gastroscopy examination. ${ }^{11-20}$ Whether this observation has a relation to the subsequent development of adenocarcinoma at this site remains to be established.

As experience with biopsy of the GOJ has grown it has been recognised that histologically the area is often characterised by a heavy chronic inflammatory cell infiltrate. ${ }^{16} 2122$ The term "carditis" has been popularised to describe these observations. ${ }^{162122}$ Early reports identified a relation between carditis and gastro-oesophageal reflux disease (GORD), ${ }^{16} 21$ while other investigators have correlated carditis with Helicobacter pylori infection. ${ }^{19}$ Despite these observations there is considerable confusion over what constitutes inflammation within the mucosa of the GOJ.

The purpose of this study was to use a previously validated scoring system (updated Sydney System $)^{23} 24$ to describe the patterns of gastritis in patients with symptomatic GORD. Particular reference was given to inflammation at the GOJ and its relation to $H$ pylori infection.

\section{Patients and methods}

Patients undergoing gastroscopy at our institution between November 1996 and July 1998 for the symptoms of GORD, defined by a history of heartburn and/or regurgitation at least twice weekly for at least three months were invited to participate in the study. Exclusion criteria were a past history of foregut surgery apart from cholecystectomy; malignant disease; anticoagulant therapy; and $H$ pylori eradication therapy within the previous three

Abbreviations used in this paper: GOJ, gastro-oesophageal junction; GORD, gastro-oesophageal reflux disease. 
months. The study was approved by Bro-Taf Local Research Ethics Committee; each patient gave informed consent.

\section{ENDOSCOPY}

Proton pump inhibitors were discontinued for two weeks prior to endoscopy and $\mathrm{H}_{2}$ receptor antagonists for 48 hours. We postulated that cardiac mucosa would behave in a similar fashion to antral mucosa. ${ }^{25}$ An earlier pilot study had indicated a $98 \%$ concordance rate between urea breath test and antral biopsy culture, for the detection of $\mathrm{H}$ pylori, when antisecretory therapy had been discontinued according to the above guidelines. ${ }^{26}$ Cessation of proton pump inhibitor therapy for shorter intervals was associated with lower concordance rates.

Endoscopy was performed in a standard fashion, with visualisation of the oesophagus, stomach, and duodenum. The presence of oesophagitis was identified and graded according to the Savary-Miller classification. Barrett's oesophagus was defined according to the American College of Gastroenterology guidelines as "a change in the oesophageal epithelium of any length that can be recognised at endoscopy and is confirmed to have intestinal metaplasia by biopsy". ${ }^{27}$ Barrett's oesophagus was defined as long segment when at least $3 \mathrm{~cm}$ in its endoscopic extent, and short segment Barrett's when less than $3 \mathrm{~cm}$ in length.

BIOPSY PROTOCOL

In subjects with no endoscopically visible columnar lining to their lower oesophagus, biopsy specimens were obtained from the GOJ $(n=3)$, the mid posterior wall of the gastric corpus $(n=2)$, and the prepyloric antrum $(n=2)$. Specimens from the GOJ were obtained using the retroflexed endoscope, attempting to include the squamocolumnar junction (Z-line) within the biopsy samples. For patients with a visible columnar lining in their lower oesophagus, the GOJ specimens were obtained from the point where the tubular oesophagus blended with the gastric rugal folds. These patients had additional four quadrant biopsy specimens taken, every $2 \mathrm{~cm}$ along the columnar segment.

\section{HISTOLOGY}

Biopsy specimens were fixed in $4 \%$ buffered formalin, embedded in paraffin wax, sectioned, and mounted on glass slides. Sections were stained with haematoxylin and eosin, and Giemsa.

Fundic mucosa was defined histologically by the presence of straight, tightly packed tubular glands composed of parietal and chief cells. Cardiac and antral mucosae were identified by their tubular or coiled racemose glands composed of mucus secreting cells. ${ }^{28}$ In some patients, cardiac and antral mucosae contained small numbers of parietal cells. Intestinal metaplasia was defined by the presence of goblet cells in glandular mucosa (specialised intestinal metaplasia). Alcian blue ( $\mathrm{pH}$ 2.5)/ periodic acid Schiff staining was employed in selected cases where there was uncertainty about the presence of intestinal metaplasia, which was then defined by the presence of goblet cells containing alcianophilic acid mucins.

Sections were reviewed by a single pathologist who was blinded to the endoscopic findings. For each section the mucosal type was recorded (cardiac, fundic, antral). The degree of neutrophil infiltration and the degree of lamina propria mononuclear cell infiltration were graded $0-3$ according to the updated Sydney System. ${ }^{23}$ The presence of intestinal metaplasia was recorded as present or absent. Where there was disparity within sections between biopsy specimens from a single anatomical site, the score for the most abnormal area was recorded. The presence of $H$ pylori in any Giemsa stained section from the cardia, corpus, or antrum was considered diagnostic of infection.

Following initial histological examination of sections from all patients, adjacent sections of biopsy specimens showing intestinal metaplasia were stained with high iron diamine/alcian blue ( $\mathrm{pH}$ 2.5) in order to identify sulphomucin expressing incomplete intestinal metaplasia (type 3 intestinal metaplasia). ${ }^{29} 30$

In the Results, biopsy location has been termed anatomically as GOJ, gastric corpus, or gastric antrum; mucosal type has been termed squamous, cardiac, fundic, or antral. Carditis has been used to indicate inflammation in cardiac mucosa, but not fundic mucosa, located at the GOJ.

STATISTICS

Continuous data were compared using the Mann-Whitney U test. Comparison of proportions was by Fisher's exact test or the $\chi^{2}$ test. Significance was taken at the $5 \%$ level.

\section{Results}

The study population comprised 150 patients with reflux symptoms (90 men, 60 women) of median age 57 years (range $21-85$ ). No patient had previously undergone gastroscopy. Sixty six patients had been taking proton pump inhibitors and $26, \mathrm{H}_{2}$ receptor antagonists. The remaining 58 patients had not received any form of antisecretory therapy. The endoscopic findings were: 89 (59\%) grade 0/I oesophagitis, $30(20 \%)$ grade II/III oesophagitis, and 31 (21\%) grade IV oesophagitis. The 31 patients with grade IV oesophagitis comprised seven patients with peptic strictures and 24 patients with Barrett's oesophagus; in 16 patients this was long segment in type, and in the remaining eight, it was short segment in type.

Overall, 44 patients were colonised with $H$ pylori $(29 \%)$. Bacteria were identified at all three sites (GOJ, corpus, and antrum) in 30 patients $(68 \%)$. According to anatomical location the rates of $H$ pylori colonisation were $34 / 44(77 \%)$ for the GOJ, $41 / 44(93 \%)$ for the corpus, and $39 / 44(89 \%)$ for the antrum. There were no significant differences in the colonisation rates of patients with GORD when stratified according to Savary-Miller grade of oesophagitis: grades 0 and I (28/89, $31 \%)$, grades II and III $(5 / 30,17 \%)$, and grade IV $(11 / 31,35 \%)$. 


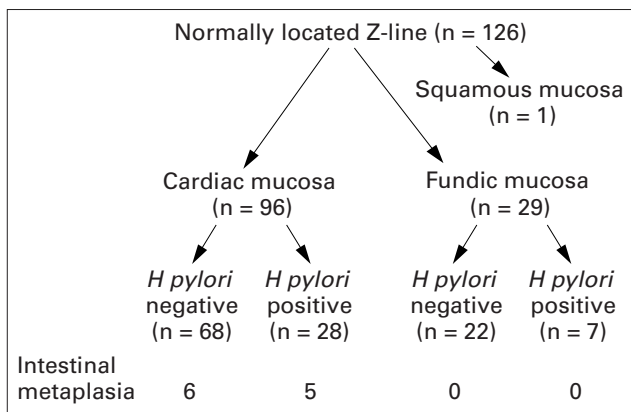

Figure 1 Histology of gastro-oesophageal junction biopsy specimens for the 126 patients with a normally located $Z$-line. Patients have been subdivided according to mucosal type (cardiac, fundic, squamous) and Helicobacter pylori status. The prevalence of intestinal metaplasia in the gastro-oesophageal junction specimens is indicated.

In the 126 patients with a normally positioned Z-line, biopsy specimens from the GOJ revealed cardiac mucosa in 96 patients $(76 \%)$, fundic mucosa in 29 patients (23\%), and squamous mucosa in one patient $(1 \%)$. Figure 1 summarises these findings and indicates the $H$ pylori status of the patients. In 54 of the 126 subjects $(43 \%)$ with a normally located Z-line, the squamocolumnar junction was present in the histological sections. In all patients the junction comprised a squamous to cardiac mucosal interface. There were no examples of a squamous to fundic mucosal interface in these patients - that is, none of the 29 patients with fundic mucosa in biopsy specimens from the GOJ had the squamocolumnar junction included in the histological sections.

Inflammatory cell infiltration was present in 99/125 (79\%) GOJ biopsy specimens, including $87 / 96(91 \%)$ specimens with cardiac mucosa and $12 / 29$ (41\%) specimens with fundic mucosa $(\mathrm{p}<0.01)$. Inflammation of fundic mucosa was closely related to $H$ pylor $i$ infection (fig 2) and active inflammation with neutrophils was only seen in the presence of this organism. Inflammation of cardiac mucosa at the GOJ was less closely linked to $H$ pylori. When the organism was present $(28 / 96,29 \%)$ active inflammation was almost invariably present $(25 / 28,89 \%)$. However, active inflammation was also found in $34 / 68(50 \%)$ cardiac biopsy specimens without $H$ pylori. Overall, 28/87 (32\%) GOJ biopsy specimens with carditis were colonised by $H$ pylori and $59 / 87$ $(68 \%)$ were not.

In $H$ pylori colonised patients inflammation was observed throughout the stomach in each of the three mucosal types (table 1). In contrast, in uncolonised patients, inflammation was confined to cardiac mucosa. Figures 3 and

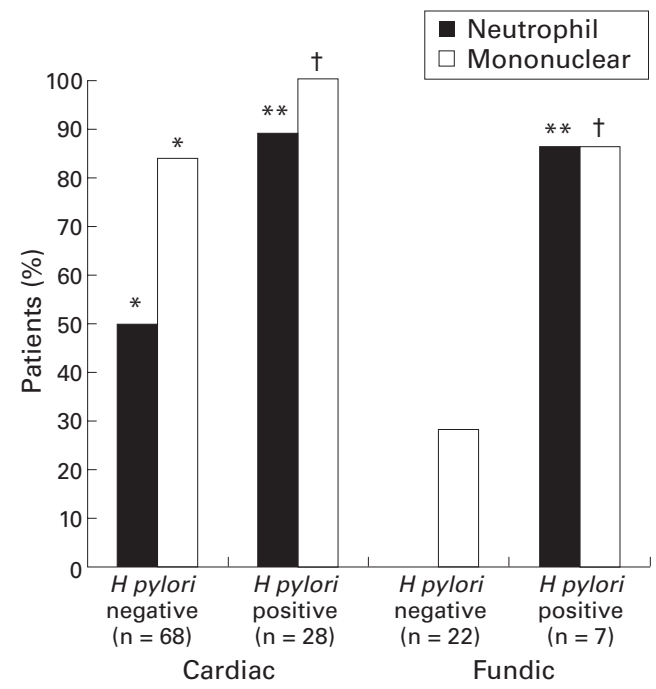

Figure 2 Prevalence of neutrophil and mononuclear cell infiltration in columnar mucosa obtained from biopsy specimens of the gastro-oesophageal junction in 126 patients with a normally positioned $Z$-line. For each type of columnar mucosa prevalence of inflammatory cell infiltration is presented according to the presence or absence of Helicobacter pylori infection. Note the high prevalence of acute and chronic inflammation in cardiac type mucosa which was unrelated to $H$ pylori. ${ }^{*} p<0.05$ v fundic $H$ pylori negative, ${ }^{*} p<0.01$ v cardiac $H$ pylori negative or fundic $H$ pylori negative, $t p<0.01$ v fundic $H$ pylori negative.

4 show the prevalence of neutrophil and mononuclear cell infiltration throughout the stomach according to $H$ pylori status. Unlike cardiac mucosa, active inflammation with neutrophils was almost never seen in fundic or antral mucosae in the absence of $H$ pylori.

Table 2 compares the severity of neutrophil and mononuclear cell infiltration for the three mucosal types according to $H$ pylori status. Compared with fundic and antral mucosae the density of neutrophil and mononuclear cell infiltrate was significantly greater in cardiac mucosa in patients without evidence of $\mathrm{H}$ pylori colonisation $(\mathrm{p}<0.01)$.

INTESTINAL METAPLASIA AT THE GOJ

Biopsy specimens of the anatomical GOJ from the 24 patients with Barrett's oesophagus revealed cardiac mucosa in 17 patients and fundic mucosa in seven. Intestinal metaplasia was present within these specimens in $11 / 17$ with cardiac type mucosa and $0 / 7$ with fundic type mucosa.

Of the 126 patients with a normal appearing Z-line the GOJ biopsy specimens showed intestinal metaplasia in 11 (9\%; fig 1). Intestinal metaplasia was present in $11 / 96$ patients

Table 1 Relation between histology of cardiac mucosa and more distal gastric mucosa

\begin{tabular}{llll}
\hline Appearance of cardiac mucosa & $\begin{array}{l}\text { Inflammation in cardiac } \\
\text { mucosa }(\%)\end{array}$ & $\begin{array}{l}\text { Inflammation in fundic } \\
\text { mucosa (\%) }\end{array}$ & $\begin{array}{l}\text { Inflammation in antral } \\
\text { mucosa (\%) }\end{array}$ \\
\hline Normal $(\mathrm{n}=9)$ & $0(0 \%)$ & $1(11 \%)$ & $1(11 \%)$ \\
H pylori negative carditis $(\mathrm{n}=59)$ & $59(100 \%)^{\star \star}$ & $12(20 \%)$ & $18(31 \%)$ \\
H pylori positive carditis $(\mathrm{n}=28)$ & $28(100 \%)$ & $28(100 \%)$ & $27(96 \%)$ \\
\hline
\end{tabular}

There was no significant difference in median age between the three groups: no carditis ( 52 years), $H$ pylori negative carditis ( 57 years), $H$ pylori positive carditis (62 years).

Identification of $H$ pylori organisms in any biopsy specimen from either the gastro-oesophageal junction, corpus, or antrum was considered diagnostic of infection. Organisms were identified with the following frequency: cardiac mucosa $(21 / 28,75 \%)$, fundic mucosa $(27 / 28,96 \%)$, antral mucosa $(23 / 28,82 \%)$.

$\star \star \mathrm{p}<0.01$ versus fundic mucosa and versus antral mucosa. 


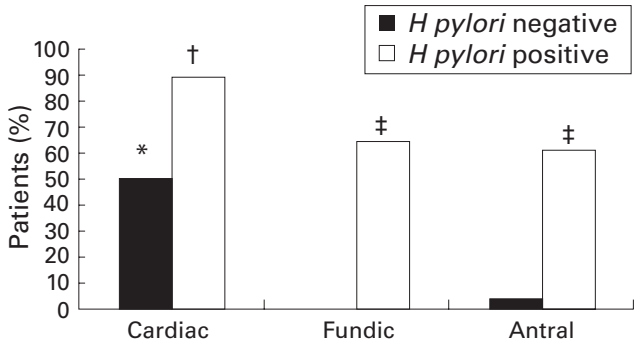

Figure 3 Prevalence of neutrophil infiltration in columnar mucosa at different locations throughout the stomach for 96 patients with reflux symptoms and cardiac type mucosa on biopsy of the gastro-oesophageal junction. The patients are stratified into Helicobacter pylori positive $(n=28)$ and $H$ pylori negative $(n=68)$. ${ }^{\star} p<0.05 v$ fundic $H$ pylori negative and antral $H$ pylori negative, $t p<0.05 v$ all sites in non-colonised individuals, $\neq p<0.05$ v fundic $H$ pylori negative and antral $H$ pylori negative.

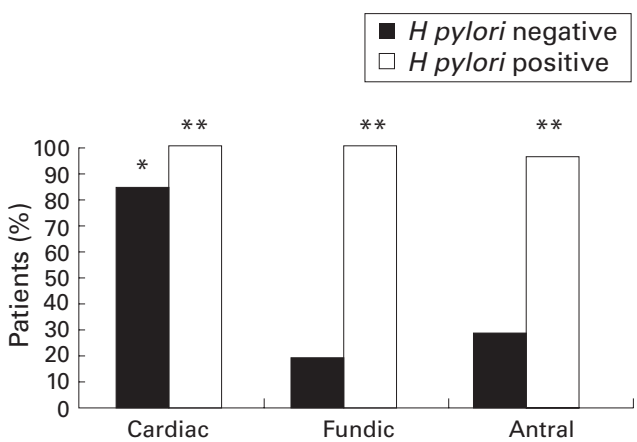

Figure 4 Prevalence of mononuclear cell infiltration in columnar mucosa at different locations throughout the stomach for 96 patients with reflux symptoms and cardiac type mucosa on biopsy of the gastro-oesophageal junction. The patients are stratified into Helicobacter pylori positive $(n=28)$ and $H$ pylori negative $(n=68) .{ }^{*} p<0.05 v$ fundic $H$ pylori negative and antral $H$ pylori negative, ${ }^{\star \star} H$ pylori positive versus $H$ pylori negative.

with cardiac mucosa but in $0 / 29$ patients with fundic mucosa at the GOJ. There was no significant difference in the prevalence of intestinal metaplasia in cardiac mucosa between patients colonised with $H$ pylori $(5 / 28,18 \%)$ and non-colonised patients $(6 / 68,9 \%)$. The

Table 2 Comparison of the severity of acute and chronic inflammation in 96 patients with cardiac type mucosa at the GOF stratified according to mucosal type and Helicobacter pylori status

\begin{tabular}{|c|c|c|c|c|c|c|}
\hline & \multicolumn{3}{|c|}{ H pylori negative } & \multicolumn{3}{|c|}{ H pylori positive } \\
\hline & Cardiac & Fundic & Antral & Cardiac & Fundic & Antral \\
\hline \multicolumn{7}{|c|}{ Neutrophil infiltration } \\
\hline None & $34(50 \%)$ & $68(100 \%)$ & $65(96 \%)$ & $3(11 \%)$ & $10(36 \%)$ & $11(39 \%)$ \\
\hline Low & $17(25 \%)$ & $0(0 \%)$ & $1(1 \%)$ & $8(29 \%)$ & $3(11 \%)$ & $5(18 \%)$ \\
\hline Moderate & $15(22 \%)$ & $0(0 \%)$ & $1(1 \%)$ & $13(46 \%)$ & $9(32 \%)$ & $7(25 \%)$ \\
\hline Heavy & $2(3 \%)$ & $0(0 \%)$ & $1(1 \%)$ & $4(14 \%)$ & $6(21 \%)$ & $5(18 \%)$ \\
\hline \multicolumn{7}{|c|}{ Mononuclear cell infiltration } \\
\hline None & $11(16 \%)$ & $55(81 \%)$ & $49(72 \%)$ & $0(0 \%)$ & $0(0 \%)$ & $1(4 \%)$ \\
\hline Low & $35(51 \%)$ & $9(13 \%)$ & $13(19 \%)$ & $5(18 \%)$ & $7(25 \%)$ & $4(14 \%)$ \\
\hline Moderate & $18(26 \%)$ & $4(6 \%)$ & $5(7 \%)$ & $15(54 \%)$ & $11(39 \%)$ & $14(50 \%)$ \\
\hline Heavy & $4(6 \%)$ & $0(0 \%)$ & $1(1 \%)$ & $8(29 \%)$ & $10(36 \%)$ & $9(32 \%)$ \\
\hline
\end{tabular}

Table 3 Prevalence of type 3 intestinal metaplasia (IM) according to biopsy location for all 150 patients

\begin{tabular}{lllll}
\hline & Oesophagus & GOf & Corpus & Antrum \\
\hline Prevalence of type 3 IM (\%) & $15 / 24(63 \%)^{\star \star}$ & $9 / 18(50 \%) \dagger$ & $0 / 7(0 \%)$ & $3 / 15(20 \%)$
\end{tabular}

For each biopsy location, the denominator is the number of patients with intestinal metaplasia at this site. Some patients had intestinal metaplasia at more than one location.

$\chi^{2}=12.6(3 \mathrm{df}), \mathrm{p}<0.01$

${ }^{\star} \mathrm{p}<0.01$ versus corpus and $\mathrm{p}<0.05$ versus antrum, $\dagger \mathrm{p}<0.05$ versus corpus.

GOJ, gastro-oesophageal junction. prevalence of cardia intestinal metaplasia in patients with grades 0 and I oesophagitis $(7 / 89$, $8 \%$ ) and those with grades II and III oesophagitis $(4 / 30,13 \%)$ was not significantly different. Patients with cardia intestinal metaplasia were more likely to have intestinal metaplasia identified at more distal gastric sites $(5 / 11,45 \%)$ than patients without cardia intestinal metaplasia $(12 / 114,11 \% ; \mathrm{p}<0.01)$.

Table 3 shows the prevalence of type 3 intestinal metaplasia according to biopsy location for all patients in whom intestinal metaplasia was identified. There was a high frequency of type 3 intestinal metaplasia in the oesophagus and GOJ, but a low frequency in the distal stomach.

\section{Discussion}

Using a previously validated scoring system for the assessment of gastritis, ${ }^{23}{ }^{24}$ our study identified two distinct patterns of carditis in patients with symptomatic GORD. One was associated with $H$ pylori infection and was characterised by inflammation in cardiac, fundic, and antral mucosae (pangastritis). The other, which was unassociated with $H$ pylori infection, comprised inflammation confined to cardiac mucosa (isolated carditis).

There is controversy about the aetiology of carditis; both GORD ${ }^{16}$ and $H$ pylori infection ${ }^{19}$ have been suggested. In a report by Oberg et $a l,{ }^{16}$ inflammation in cardiac mucosa was shown in $237 / 246$ patients $(96 \%)$ with foregut symptoms. Its presence was significantly associated with defective lower oesophageal sphincter function, but not increased oesophageal acid exposure. The investigators found no significant association between carditis and $H$ pylori colonisation. In contrast, Goldblum and colleagues ${ }^{19}$ found no difference in the prevalence of carditis between 58 patients with reflux symptoms $(40 \%)$ and 27 control subjects $(41 \%)$. As all except one patient with carditis was $H$ pylori colonised, the authors concluded that $H$ pylor $i$ was the principal cause of carditis.

There have been two additional publications describing carditis. ${ }^{31}{ }^{32}$ Both evaluated only $H$ pylori colonised patients. Genta and colleagues ${ }^{31}$ were the first to report that cardiac mucosa was as frequently colonised by the bacterium as mucosa from more distal gastric sites. The authors observed a similar intensity of inflammatory response in cardiac and antral mucosa, both being greater than that seen in fundic mucosa. In the second study, Hackelsberger and colleagues ${ }^{32}$ found a lower density of $H$ pylori colonisation in the cardiac mucosa of patients with erosive oesophagitis compared with the bacterial density in other gastric mucosal types.

In our study, when cardiac mucosa was identified at the GOJ of patients with a normally located Z-line, inflammation was present in $91 \%$ (87/96). It was H pylori associated in one third of patients and was unassociated in the remaining two thirds. By comparison, when fundic mucosa was identified at this site, inflammation was more closely related to $H$ pylor $i$ infection. Indeed, active inflammation 
with neutrophils was only seen in the presence of this organism.

Based on our observations, it appears that there are three possibilities. Firstly, that all carditis is due to $H$ pylori, but that we failed to identify the organism in two thirds of the patients. This seems unlikely as the sensitivity and specificity of Giemsa staining for the detection of $\mathrm{H}$ pylori are around $90 \%$ and $98 \%$ respectively based on biopsy specimens from one or two locations. ${ }^{33-35}$ In our study, biopsy specimens were obtained from three locations. Furthermore, inflammation in all three mucosal types would be expected if $H$ pylori were responsible. The second possibility is that carditis is completely unrelated to $H$ pylori. Its identification in one third of patients with carditis is merely coincidental, because this is the frequency of $\mathrm{H}$ pylori colonisation in our study population. Indeed, this value is in agreement with previous studies reporting the prevalence of $H$ pylori in Western populations. ${ }^{36-39}$ The third possibility and our favoured explanation is that there are two causes for carditis, $H$ pylori being implicated in one third of cases and another agent in the remaining two thirds. Gastro-oesophageal reflux, in particular bile reflux, has been proposed as a cause of carditis. However, if reflux carditis is the analogue of antral bile reflux gastritis, its histological hallmarks should be a paucicellular response. ${ }^{40-43}$ As this is not the case, it seems unlikely that bile reflux alone is responsible. It is possible, however, that bile reflux increases the susceptibility of cardiac mucosa to injury by another agent. Purely on histological grounds, it appears that this second agent causes carditis by a mechanism similar to $H$ pylori, given that $H$ pylori negative and $H$ pylori positive carditis were morphologically indistinguishable except on Giemsa staining.

We identified unsuspected intestinal metaplasia at the GOJ in $11 / 126$ patients $(9 \%)$. This has been termed ultra short segment Barrett's oesophagus and has been noted by other investigators with a frequency ranging from 6 to $36 \%$ (median 13\%). ${ }^{11-20}{ }^{44-46}$ The significance of ultra short segment Barrett's oesophagus is unclear as its relation to adenocarcinoma of the GOJ remains unknown. We did not identify a significant association between $H$ pylori infection and intestinal metaplasia at the GOJ. Previous reports examining this association have yielded conflicting results, with four of the eight papers reporting negative findings, ${ }^{15-17} 45$ and the other four, positive findings. ${ }^{14} 192046$

The origin and nature of cardiac mucosa itself has been a source of controversy, some investigators believing it to arise by metaplasia of oesophageal squamous mucosa as a response to reflux disease. We, however, consider cardiac mucosa to be a normal finding. Supportive evidence for this is fivefold. Firstly, although it was symptomatic individuals that we studied, when the squamocolumnar junction was included in the histological section, it comprised squamocardiac mucosal apposition in each subject. Secondly, biopsy specimens of the GOJ from 15 subjects (median age 48 years, range 20-84) free of reflux symptoms revealed squamocardiac mucosal apposition in the 12 subjects with a histologically identified squamocolumnar junction (unpublished data). Thirdly, in earlier reports, cardiac mucosa has been identified at the GOJ of healthy volunteers undergoing endoscopy and biopsy. ${ }^{47}{ }^{48}$ Fourthly, postmortem examination of the GOJ in foetuses, neonates, children, and adults has consistently revealed a zone of cardiac mucosa. ${ }^{49-54}$ Finally, cardiac mucosa has been identified in every mammal studied to date. ${ }^{49-5155}$

For intestinal metaplasia of the distal stomach, it is the sulphomucin expressing form (type 3) that has been most closely linked to adenocarcinoma at this site, with little or no excess risk apparent for types 1 and 2 intestinal metaplasia. ${ }^{56}{ }^{57}$ Patients with Barrett's oesophagus have been previously noted to have a high prevalence of type 3 intestinal metaplasia in the oesophagus, although cancer risk at this location remains to be quantified. ${ }^{58-62}$ In our study, we identified a high frequency of type 3 intestinal metaplasia at the GOJ, an observation not previously reported. Moreover, the proportion of type 3 metaplasia at the GOJ $(50 \%)$ was similar to that found in the oesophagus $(63 \%)$. This is noteworthy given the epidemiological similarities between adenocarcinoma arising in the oesophagus and that arising at the GOJ. ${ }^{12}$ We speculate that it is patients with type 3 intestinal metaplasia at the GOJ who are at increased risk for the development of malignancy at this site. The results of surveillance studies of such patients are awaited to confirm or refute this hypothesis.

In summary, this study, which is the first to document carefully the histological features of the entire stomach in patients with symptomatic GORD, indicates a high frequency of carditis in this population. The carditis appears to be of two aetiological types, one $H$ pylori associated, the other unassociated. The challenge before us is to elucidate the nature and cause of non- $H$ pylori carditis.

D J Bowrey was salaried by a Royal College of Surgeons of England/Welsh Office Research Fellowship. Laboratory costs were funded by a grant from the Wales Office of Research and Development for Health and Social Care.

1 Powell J, McConkey CC. Increasing incidence of adenocarcinoma of the gastric cardia and adjacent sites. Br F Cancer 1990;62:440-3.

2 Blot WJ, Devesa SS, Kneller RW, et al. Rising incidence of adenocarcinoma of the esophagus and gastric cardia. ҰAMA 1991;265:1287-9.

3 Cameron AJ, Ott BJ, Payne WS. The incidence of adenocarcinoma in columnar-lined (Barrett's) esophagus. adenocarcinoma in columnar-

4 Hameeteman W, Tytgat GN, Houthoff HJ, et al. Barrett's esophagus: development of dysplasia and adenocarcinoma. Gastroenterology 1989;96:1249-56.

5 Van der Veen AH, Dees J, Blankensteijn JD, et al. Adenocarcinoma in Barrett's oesophagus: an overrated risk. Gut 1989;30:14-18

6 Williamson WA, Ellis FH Jr, Gibb SP, et al. Barrett's esophagus. Prevalence and incidence of adenocarcinoma. Arch Intern Med 1991;151:2212-16.

7 Iftikhar SY, James PD, Steele RJ, et al. Length of Barrett's oesophagus: an important factor in the development of dysplasia and adenocarcinoma. Gut 1992;33:1155-8.

8 Menke-Pluymers MB, Hop WC, Dees J, et al. Risk factors for the development of an adenocarcinoma in columnar fired (Barrett) Tumor Study Group. Cancer 1993;72:1155-8.

9 Drewitz DJ, Sampliner RE, Garewal HS. The incidence of adenocarcinoma in Barrett's esophagus: a prospective study of 170 patients followed 4.8 years. Am $\mathcal{F}$ Gastroenterol study of 170 patients 
10 Katz D, Rothstein R, Schned A, et al. The development of dysplasia and adenocarcinoma during endoscopic surveillance of

11 Spechler SJ, Zeroogian JM, Antonioli DA, et al. Prevalence of metaplasia at the gastro-oesophageal junction. Lancet 1994;344:1533-6.

12 Johnston $\mathrm{MH}$, Hammond AS, Laskin W, et al. The prevalence and clinical characteristics of short segments of specialized intestinal metaplasia in the distal esophagus on routine endoscopy. Am 7 Gastroenterol 1996;91:1507-11.

13 Chalasani N, Wo JM, Hunter JG, et al. Significance of intestinal metaplasia in different areas of esophagus including esophagogastric junction. Dig Dis Sci 1997;42:603-7.

14 Morales TG, Sampliner RE, Bhattacharyya A. Intestinal metaplasia of the gastric cardia. $A m \mathcal{F}$ Gastroenterol 1997;92:414-18.

15 Nandurkar S, Talley NJ, Martin CJ, et al. Short segment Barrett's oesophagus: prevalence, diagnosis and associaBarrett's oesophagus: prevale
tions. Gut 1997;40:710-15.

16 Oberg S, Peters JH, DeMeester TR, et al. Inflammation and specialized intestinal metaplasia of cardiac mucosa is a manifestation of gastroesophageal reflux disease. Ann Surg 1997;226:522-32.

17 Trudgill NJ, Suvarna SK, Kapur KC, et al. Intestinal metaplasia at the squamocolumnar junction in patients attending for diagnostic gastroscopy. Gut 1997;41:585-9.

18 Dias Pereira A, Suspiro A, Chaves P, et al. Short segments of Barrett's epithelium and intestinal metaplasia in normal appearing oesophagogastric junctions: the same or two different entities? Gut 1998;42:659-62.

19 Goldblum JR, Vicari JJ, Falk GW, et al. Inflammation and intestinal metaplasia of the gastric cardia: the role of gastroesophageal reflux disease and $\mathrm{H}$ pylori infection. Gastroenterology 1998;114:633-9.

20 Hackelsberger A, Gunther T, Schultze V, et al. Intestinal metaplasia at the gastro-oesophageal junction: Helicobacter pylori gastritis or gastro-oesophageal reflux disease? bucter pylori gastriti

21 Clark GW, Ireland AP, Chandrasoma P, et al. Inflammation and metaplasia in the transitional epithelium of the gastroesophageal junction: a new marker for gastroesophage
reflux disease [abstract]. Gastroenterology 1994;106:A63.

22 Riddell RH. The biopsy diagnosis of gastroesophageal reflux disease, "carditis", and Barrett's esophagus, and sequelae of therapy [review]. Am f Surg Pathol 1996;20(suppl 1): $\$ 31-50$

23 Dixon MF, Genta RM, Yardley JH, et al. Classification and grading of gastritis. The updated Sydney System. Am $\mathcal{F}$ Surg Pathol 1996;20:1161-8

24 Andrew A, Wyatt JI, Dixon MF. Observer variation in the assessment of chronic gastritis according to the Sydney system. Histopathology 1994;25:317-22.

25 Bowrey DJ, Williams GT, Clark GWB. Interactions between Helicobacter pylori and gastroesophageal reflux disease [review]. Dis Esophagus 1998;11:203-9.

26 Hawthorne AB, Morgan S, Stenson R, et al. Validation of two near-patient whole blood tests for Helicobacter pylori How near are they to a gold standard? [abstract]. Gut How near are they to

27 Sampliner RE and the Practice Parameters Committee of the American College of Gastroenterology. Practice guidelines on the diagnosis, surveillance, and therapy of Barrett's esophagus. Am $\mathcal{F}$ Gastroenterol 1998;93:1028-32.

28 Owen DA. Normal histology of the stomach [review]. $A m \mathcal{F}$ Surg Pathol 1986;10:48-61.

29 Spicer SS. Diamine methods for differentiating mucosubstances histochemically. F Histochem Cytochem 1965;13 211-34.

30 Filipe $\mathrm{MI}$, Lake $\mathrm{BD}$, eds. Histochemistry in pathology. Edinburgh: Churchill Livingstone, 1983:310-13.

31 Genta RM, Huberman RM, Graham DY. The gastric cardia in Helicobacter pylori infection. Hum Pathol 1994;25:915in $\mathrm{H}$

32 Hackelsberger A, Gunther T, Schultze V, et al. Prevalence and pattern of Helicobacter pylori gastritis in the gastric and pattern of Helicobacter pylori gastriti

33 Thijs JC, van Zwet AA, Thijs WJ, et al. Diagnostic tests for Helicobacter pylori: a prospective evaluation of their accu-
racy, without selecting a single test as the gold standard. racy, without selecting a single test
Am $\mathcal{F}$ Gastroenterol 1996;91:2125-9.

34 Lerang F, Moum B, Mowinckel P, et al. Accuracy of seven different tests for the diagnosis of Helicobacter pylor infection and the impact of $\mathrm{H} 2$-receptor antagonists on test results. Scand F Gastroenterol 1998;33:364-9.

35 Luthra GK, DiNuzzo AR, Gourley WK, et al. Comparison of biopsy and serological methods of diagnosis of Helicobacter pylori infection and the potential role of antibiotics. Am f Gastroenterol 1998;93:1291-6.
36 Dooley CP, Cohen H, Fitzgibbons PL, et al. Prevalence of Helicobacter pylori infection and histologic gastritis in asymptomatic persons. N Engl f Med 1989;321:1562-6.

37 Megraud F. Epidemiology of Helicobacter pylori infection [review] Gastroenterol Clin N Am 1993;22:73-88.

38 Buckley MJM, O'Shea J, Grace A, et al. A community-based study of the epidemiology of Helicobacter pylori infection and associated asymptomatic gastroduodenal pathology. Eur $\mathcal{F}$ Gastroenterol Hepatol 1998;10:375-9.

39 Vicari JJ, Peek RM, Falk GW, et al. The seroprevalence of cagA-positive Helicobacter pylori strains in the spectrum of gastroesophageal reflux disease. Gastroenterology 1998;115: $50-7$.

40 Dixon MF, O'Connor HJ, Axon AT, et al. Reflux gastritis: distinct histopathological entity? f Clin Pathol 1986;39: $524-30$

41 Sobala GM, King RF, Axon AT, et al. Reflux gastritis in the intact stomach. F Clin Pathol 1990;43:303-6.

42 Sobala GM, O'Connor HJ, Dewar EP, et al. Bile reflux and intestinal metaplasia in gastric mucosa. 7 Clin Pathol 1993; 46:235-40.

43 Houghton PW, Mortensen NJ, Thomas WE, et al. Intragasric bile acids and histological changes in gastric mucosa. Br F Surg 1986;73:354-6.

44 Byrne JP, Bhatnagar S, Hamid B, et al. Comparative study of intestinal metaplasia and mucin staining at the cardia and esophagogastric junction in 225 symptomatic patients presenting for diagnostic open-access gastroscopy. Am f Gastroenterol 1999;94:98-103.

45 Voutilainen $M$, Farkkila $M$, Juhola $M$, et al. Specialized columnar epithelium of the esophagogastric junction: prevalence and associations. Am f Gastroenterol 1999;94: 913-18.

46 Hirota WK, Loughney TM, Lazas DJ, et al. Specialized intestinal metaplasia, dysplasia, and cancer of the esophagus and esophagogastric junction: prevalence and clinical data. Gastroenterology 1999;116:277-85.

47 Krause WJ, Ivey KJ, Baskin WN, et al. Morphological observations on the normal human cardiac glands. Anat $\operatorname{Rec} 1$ 1978;192:59-72.

48 Stachura J, Krause WJ, Ivey KJ. Endocrine cells in human cardiac glands. Folia Histochem Cytochem 1981;19:71-6.

49 Bensley RR. The cardiac glands of mammals. Am f Anat 1902;2:105-56.

50 Muller Botha GS. The gastro-oesophageal junction. Clinical applications to oesophageal and gastric surgery. London: J \& A Churchill Ltd, 1962.

51 Miyagawa Y. The exact distribution of the gastric glands in man and in certain animals. F Anat 1972;55:56-67.

52 Ellison E, Hassall E, Dimmick JE. Mucin histochemistry of the developing gastroesophageal junction. Pediatr Pathol Lab Med 1996;16:195-206.

53 Kilgore SP, Ormsby AH, Gramlich TL, et al. The gastric cardia is not a metaplastic mucosa secondary to gastroesophageal reflux disease (GERD) [abstract]. Gastroenterology 1999;116:A213.

54 Ormsby AH, Goldblum JR, Kilgore SP, et al. The frequency and nature of cardiac mucosa and intestinal metaplasia (IM) of the esophagogastric junction (EGJ): a population based study of 223 consecutive autopsies [abstract]. based study of 223 consecutive

55 Domeneghini C, Castaldo L. The endocrine cells of the bovine cardiac glands. Bas Appl Histochem 1981;25:51-66.

56 Filipe MI, Potet F, Bogomoletz WV, et al. Incomplete sulphomucin-secreting intestinal metaplasia for gastric cancer. Preliminary data from a prospective study from three centres. Gut 1985;26:1319-26.

57 Matsukura N, Suzuki K, Kawachi T, et al. Distribution of marker enzymes and mucin in intestinal metaplasia in human stomach and relation of complete and incomplete . f Natl Cancer Inst 1980;65:231-40.

58 Jass JR. Mucin histochemistry of the columnar epithelium of the oesophagus: a retrospective study. $f$ Clin Pathol 1981;34:866-70.

59 Peuchmaur M, Potet F, Goldfain D. Mucin histochemistry of the columnar epithelium of the oesophagus (Barrett's oesophagus): a prospective biopsy study. $\mathcal{F}$ Clin Pathol 1984;37:607-10

60 Haggitt RC, Reid BJ, Rabinovitch PS, et al. Barrett's esophagus. Correlation between mucin histochemistry, flow cytometry, and histologic diagnosis for predicting increased cancer risk. Am F Pathol 1988;131:53-61.

61 Lapertosa G, Baracchini P, Fulcheri E, et al. Mucin histochemical analysis in the interpretation of Barrett's esophagus. Am f Clin Pathol 1992;98:61-6.

62 Torrado J, Ruiz B, Garay J, et al. Blood-group phenotypes, sulfomucins, and Helicobacter pylori in Barrett's esophagus. Am f Surg Pathol 1997;21:1023-9. 